\title{
STABILITY AGAINST WAVES AND CURRENTS OF GRAVEL RUBBLE MOUNDS OVER PIPELINES AND FLAT GRAVEL BEDS
}

\author{
Alf Tørum ${ }^{1}$, Øivind A. Arntsen ${ }^{1}$, and Colin Kuester ${ }^{2}$
}

\begin{abstract}
For different reasons oil/gas pipelines or parts of oil/gas pipelines have to be covered with rubble mounds. The question is then what the size of the stones/gravel in the mound should be to withstand waves and currents of the area. In order to obtain more information on the stability of gravel mounds over pipelines, laboratory tests in a wave/current flume have been carried out and are summarized herein. In addition data from other similar investigations elsewhere are discussed. A brief analysis of the stability of a flat gravel bed subjected to irregular waves has also been included, using the concept of the statistical distribution of the bed shear stress.
\end{abstract}

Keywords: pipeline; waves and currents; rubble mound; stability; bed shear stress; laboratory experiments

\section{INTRODUCTION}

For different reasons, oil/gas pipelines or parts of oil/gas pipelines have to be covered with rubble mounds. The question is then what the size of the stones/gravel in the mound should be to withstand waves and currents of the area. Typical design significant wave heights and mean wave periods for North Sea conditions are $\mathrm{H}_{\mathrm{s}} \approx 10-15 \mathrm{~m}$ and $\mathrm{T}_{\mathrm{m}} \approx 10-15 \mathrm{~s}$. Typical pipeline diameters are $\mathrm{d}=20-40$ inches and typical height of the mound could be up to $(\mathrm{h}-\mathrm{hc})=1.5-2.0 \mathrm{~m}$. Typical slopes of the mound are 1:2-1:3 and typical mean stone "diameter" in the mound has been D50 $=50-100 \mathrm{~mm}$ for North Sea wave and current conditions for water depth $\mathrm{h}=40-70 \mathrm{~m}$.

In order to obtain more information on the stability of gravel mounds over pipelines, laboratory tests in a wave/current flume have been carried out and are summarized herein. In addition, data from other similar investigations elsewhere are discussed. A brief analysis of the stability of a flat gravel bed subjected to irregular waves has also been included, using the concept of the statistical distribution of the bed shear stress.

\section{PREVIOUS WORK}

There have been some previous studies on the stability of near-bed gravel structures and bed gravel protection. It has been customary to use a non-dimensional damage $S$ to define the damage on a gravel or rock structure.

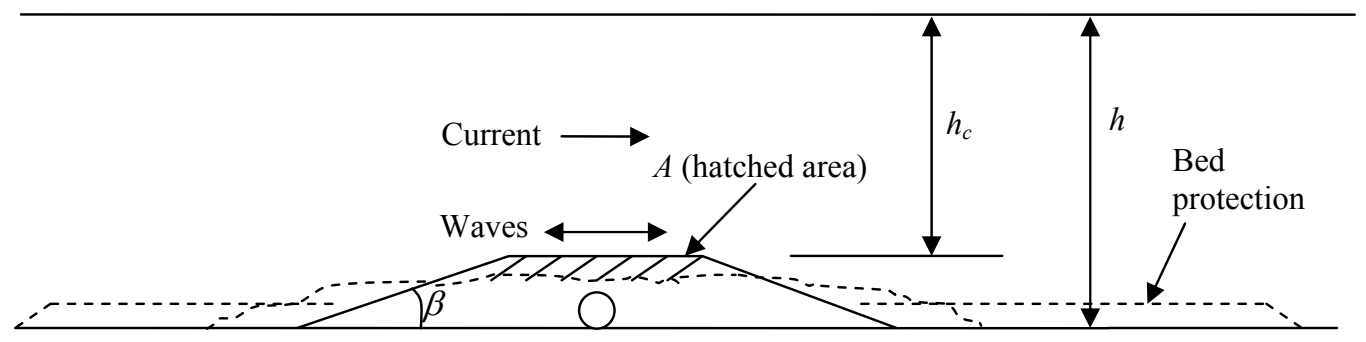

Figure 1. Definition sketch showing damage $A$ to the mound.

With reference to Figure 1, $S$ is defined as:

$$
S=\frac{A}{D_{n 50}}
$$

where $A$ is the cross-sectional damage area and $D_{n 50}=\left(W_{50} / \rho_{s}\right)^{1 / 3}$. Typical test slopes have been $1: 10<$ $\operatorname{tg} \beta<1: 1$.

Vidal et al. (1998), (2002), (2007) carried out laboratory as well as full scale tests on near bed structures and sewage outfall protection structures exposed to waves. They analyzed their test data in different ways: damage vs. a stability number $N_{s}=\left(H / \Delta D_{n 50}\right)$, damage vs. Morison force, damage vs. a

\footnotetext{
${ }^{1}$ Department and Civil and Transport Engineering, Norwegian University of Science and Technology,

7491 Trondheim, Norway

${ }^{2}$ PND Engineers, Inc., 811 First Ave, Suite 570, Seattle, WA 98104, USA
} 
mobility parameter $\theta=\tau_{b m} /\left(\rho g \Delta D_{\mathrm{n} 50}\right)$, where the maximum sea bed shear stress $\tau_{b m}$ was calculated using Eq. (5). In the analysis of their first tests, (1998) and (2002), they used the water particle velocity on the top of the mound, calculated using linear wave theory as if the water depth was $h_{c}$. In their (2007) paper they found the water particle velocity above the mound using a numerical model and applied the maximum water particle velocity at the rear edge of the mound when calculating the mobility parameter.

Lomonaco et al. (2003) discuss further the water particle velocity above the mound. Based on field measurements, they recommend that the water particle velocities as obtained from linear wave theory and with the water depth equal to the water depth above the mound are enhanced by a factor 1.41.

Lomonaco (1994) carried out tests on the stability of gravel mounds of different heights, in relation to water depth, and shape. He analyzed his data in different ways similar to Vidal et al. Lomonaco included also current in some of his tests.

Van Gent and Wallast (2001) carried out similar tests and in the same wave flume as Lomonaco (1994) on the stability of gravel mounds. They also analyzed their data in different ways, but arrived at the recommendation that the damage $S$ should be set equal to:

$$
S=0.2 M_{p}^{3} N^{0.5}
$$

where $M_{p}=\frac{u_{\delta m}^{2}}{g \Delta D_{n 50}}$ is a mobility parameter where $u_{\delta m}=\frac{\pi H_{s}}{T_{m}} \frac{1}{\cosh \left(k_{c} h_{c}\right)}$, and where $k_{c}$ is the wave number calculated using linear wave theory with wave period equal to $T_{m}$ and local water depth equal to $h_{c}$. The number of waves was typically $N=2000$.

Figure 2 shows van Gent and Wallast's results for all their tests, including currents and some of Lomonaco's (1994) data. Eq. (2) is also included in Figure 2. van Gent and Wallast stated that the influence from the current can be neglected when $U / u_{\delta m}<2.2$ for $0.15<M_{p}<3.5$.

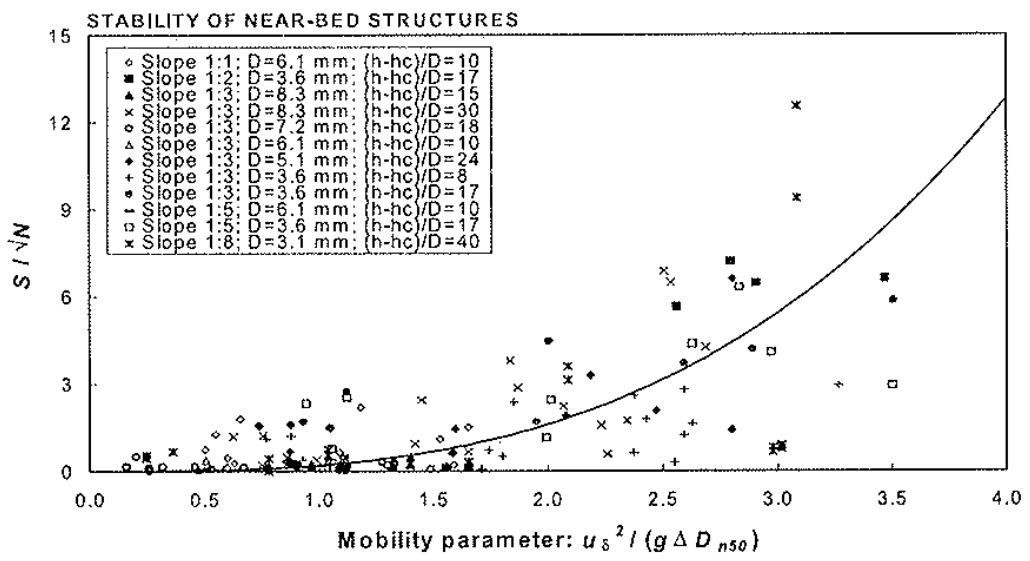

Figure 2. $S / \sqrt{N}$ as a function of the mobility parameter $\mathbf{M}_{\mathbf{p}}$. Tests with and without a current. After van Gent and Wallast (2001).

It is noted that there is inherent scatter of the data. This is normally the case when testing the stability of granular material (breakwaters, etc), but it could also reflect an improper model for the analysis. It is also noted that for small values of the mobility parameter (less than 1.0), Eq. (2) could under-predict the damage.

It is this method of van Gent and Wallast (2001) that is recommended in the newly published rock manual CIRIA, CUR, CETMEF (2007). The following is quoted from this manual, with referenced equation and figures from this present paper:

"Eq. (2) is the best fit on the measured values from model tests. Spreading exists around the predicted values, see Figure 2. The difference between the predictions of $S / \sqrt{N}$ and existing data are characterized by a standard deviation of $\sigma=1.54$ for conditions with waves only and $\sigma=1.58$ for conditions with waves in combination with a current." ... "A way to take the spreading into account for design purposes is by using an additional factor, $\alpha$, with a value of $\alpha=3.0$ in Eq. (2)" giving:

$$
\frac{S}{\sqrt{N}}=\alpha 0.2 M_{p}^{3}=0.6 M_{p}^{3}
$$


As for mounds covering oil and gas pipelines the acceptable damage $S$ should be rather low, $S<50$ or $S / \sqrt{N} \approx 1.0$ assuming $N=2000$. Hence the results for small values of the mobility parameter are of main interest. Eqs. (2) and (3) may not be adequate for the lower range of the mobility parameter $M_{p}$. This issue will be addressed later.

\section{TESTS AT NTNU (2007)}

\section{Test set-up}

In view of the diverging results from previous investigations it was decided to carry out additional tests and analysis at NTNU on the stability of rock mounds over pipelines in fairly deep water. The objective of the investigation was to arrive at improved design tools for the design of "near-bedstructures". The results of the tests may be a basis for probabilistic or performance design analysis of gravel fill over pipelines. However, such analysis has not been carried out within this project.

Details of the tests and data analysis are found in Tørum, Kuester and Arntsen (2008). The tests were carried out in a wave/current flume shown schematically in Figure 3. The flume is $26.5 \mathrm{~m}$ long, $0.60 \mathrm{~m}$ wide and $0.70 \mathrm{~m}$ deep. The water depth during the tests was $0.50 \mathrm{~m}$. At one end is a wave generator capable of generating regular and irregular waves. At the opposite end is a parabolic "beach" to absorb wave energy and create as little wave reflections as possible in the flume. Three wave gauges were positioned in the flume to measure the surface elevation at three points.

A 50-cm diameter return pipe, a flow impeller, and the various connections at either end created a circulation flow in the flume/pipe system. With a flume water depth of $0.5 \mathrm{~m}$, this system is capable of producing a current up to $60 \mathrm{~cm} / \mathrm{s}$. Currents were measured by an Acoustic Doppler Velocity meter. The given current $U$ in this paper is a cross-sectional average without waves.

The setup for these tests included two model mounds tested concurrently. They were spaced approximately 5 meters apart near the center of the flume, with one wave gauge before the first mound, one between the mounds, and one after the second. The mounds were built trapezoidal in section, with heights of $\left(h-h_{c}\right)=5 \mathrm{~cm}$ and flat tops $B=7.5 \mathrm{~cm}$ wide. The first mound had slopes of $\operatorname{tg} \beta=1: 3$ and the second mound has slopes of $\operatorname{tg} \beta=1: 2$. The profiles of the mounds were measured with a laser system, guided on a track above at various cross-sections. The ratio of the mound crest height and the water depth, $\left(h-h_{c}\right) / h$, is $5 / 50=0.1$. Coarse sand with sieve diameter $D_{50}=1.9 \mathrm{~mm}$ with gradation factor $f_{g}=$ $D_{85} / \mathrm{D}_{15} \approx 3.1$ was used as mound material. $D_{50}$ corresponds approximately to $1.2 \cdot D_{n 50}$. The mass density of the stones was measured to $\rho_{s}=2800 \mathrm{~kg} / \mathrm{m}^{3}$.

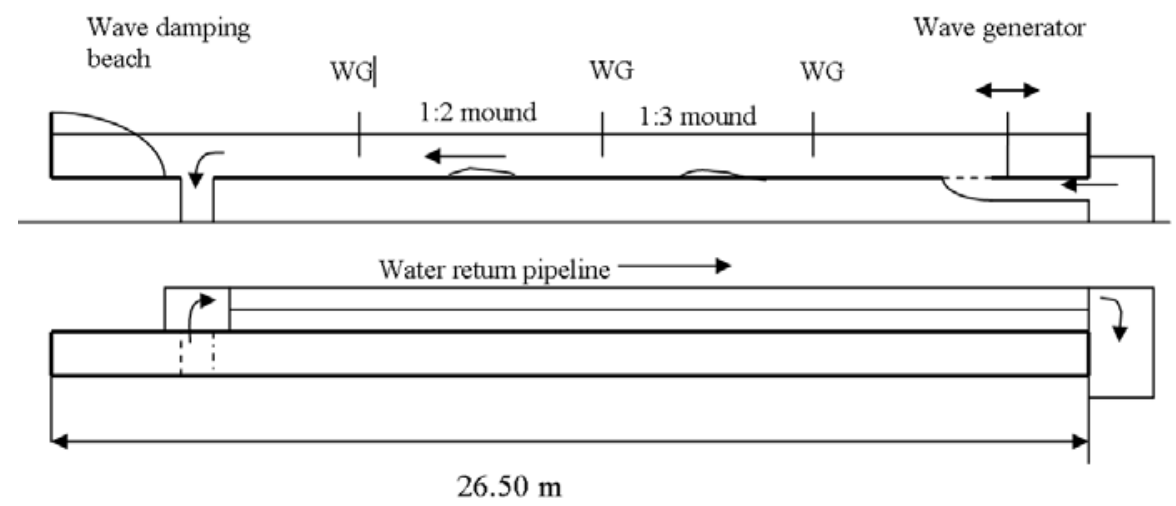

Figure 3. The wave/current flume, elevation and plan view, schematically shown. The mounds were located 5 $\mathrm{m}$ apart. WG = wave gauge

\section{ANALYSIS RESULTS AND DISCUSSIONS}

\section{Analysis of mound data}

The data analysis was performed to compare the data obtained in these tests to the data obtained by van Gent and Wallast (2001). It was noted that damage occurred only when a current was present, except one test. This is somewhat contradictory to the statement of van Gent and Wallast (2001) that the current had no significant influence on the damage. The damage parameter $S / \sqrt{N}$ vs. the mobility parameter $M_{p}$ is shown in Figure 4. Data from van Gent and Wallast (2001) tests are also included in Figure 4. Eq. (3) is also shown in the same figure. In Figure 5, data for the "No current" cases are 
shown. The Lomonaco (1994) data are for Structures No. 4 and 6 with height 0.05 and $0.125 \mathrm{~m}$ respectively.

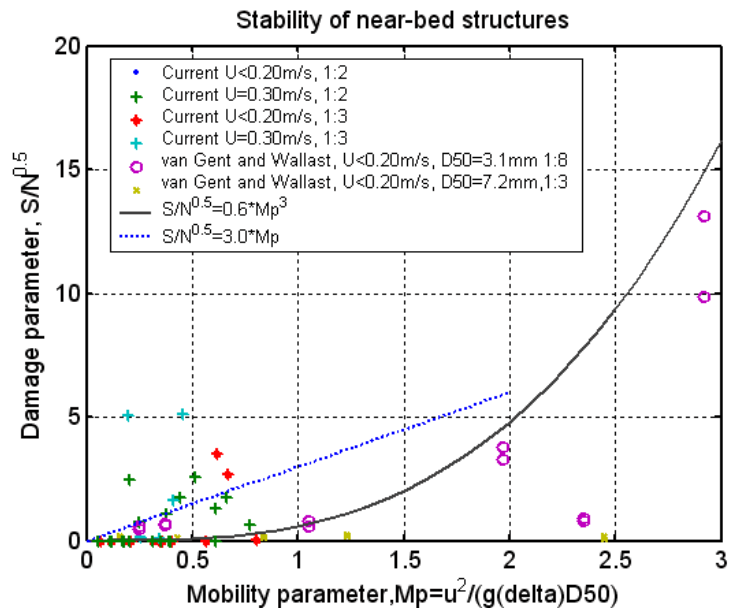

Figure 4. Damage as function of the mobility parameter. The damage parameter is $S / \sqrt{N}$ (van Gent and Wallast's definition). Own data and data from van Gent and Wallast (2001).

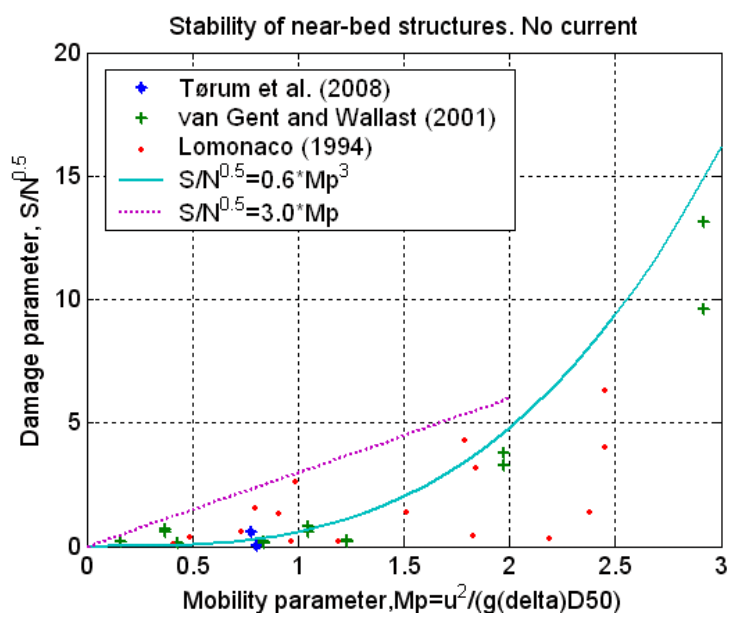

Figure 5. Damage as function of the mobility parameter. The damage parameter is $S / \sqrt{N}$ (van Gent and Wallast's definition). No current. Own data and data from Lomonaco (1994) and from van Gent and Wallast (2001).

The tests with rather high velocity, $U=30 \mathrm{~cm} / \mathrm{s}$, show a rather high damage. This is because the current alone is then nearly able to move the stones. The waves will then tend to stir up the grains and the current is then more easily able to move them. The ratio of the current velocity $U$ and the wave induced water particle velocity amplitude $u_{\delta m}$ is then $U / u_{\delta m}=2.41$ and is outside the range where van Gent and Wallast stated that the influence from the current is negligible. Also, as shown in Table 1 (see later), $U / u_{\delta m}=2.41$ is much higher than will be the case for "deep" North Sea conditions. Hence for "deep" North Sea design conditions the test results with the high velocities can be discarded. Tests with $U=50 \mathrm{~cm} / \mathrm{s}$ showed considerable damage with the current alone.

It is interesting to note the significant differences of van Gent and Wallast's results for slope $\operatorname{tg} \beta=1: 8, \mathrm{D}_{50}=3.1 \mathrm{~mm}$ and slope $\operatorname{tg} \beta=1: 3, \mathrm{D}_{50}=7.2 \mathrm{~mm}$. This is an indication that the analysis method should be revisited.

Other data was included by van Gent and Wallast (2001), see Figure 2. An upper bound for damage when $M_{p}<2.0$ is given by: 


$$
\frac{S}{\sqrt{N}}=3.0 M_{p}
$$

Eq. (4) is also shown in Figures 4 and 5. Note that the mobility parameter is defined solely from wave parameters and that current parameters are not included in its definition.

Another aspect that may be of interest is to consider the wave induced water particle displacement amplitude $A_{\delta m}$ vs. grain diameter $D_{50}, A_{\delta m}$ vs. mound width $B$, and the current velocity $U$ vs. wave induced particle velocity amplitude $u_{\delta m}$ for model and prototype conditions. This has been done as shown in Table 1 for two tests and for a prototype condition. Van Gent and Wallast (2001) states that the influence of the current can be neglected when $U / u_{\delta m}<2.2$ for $0.15<M_{p}<3.5$. This would be the case for the prototype condition shown in Table 1 . For Test 17 with a ratio $U / u_{\delta m}=2.41$ it was seen that the damage was not acceptable because of the high current velocity. Test 16 and the prototype conditions come in this case closest to each other with respect to $U / u_{\delta m}, A_{\delta m} / D_{50}$ and $A_{\delta m} / B$. However, it is not exactly known how important this issue is with respect to the stability.

\begin{tabular}{|l|l|l|l|l|l|l|l|l|}
\hline \multicolumn{7}{|c|}{ Table 1. Model vs. prototype. Width of berm = B. $\boldsymbol{B}_{\text {model }}=\mathbf{0 . 0 7 5} \mathbf{~ m}, \boldsymbol{B}_{\text {prototype }}=2.0 \mathbf{~ m}}$. \\
\hline & $H_{s}(\mathrm{~m})$ & $T_{m}(\mathrm{~s})$ & $u_{d m}(\mathrm{~m} / \mathrm{s})$ & $U(\mathrm{~m} / \mathrm{s})$ & $U / u_{d m}$ & $A_{d m}(\mathrm{~m})$ & $A_{\delta m} / D_{50}$ & $A_{\delta m} / B$ \\
\hline Model & & & & & & & & \\
Test 16 & 0.093 & 1.40 & 0.148 & 0.1 & 0.67 & 0.033 & 17.4 & 0.44 \\
Test 17 & 0.078 & 1.38 & 0.124 & 0.3 & 2.41 & 0.027 & 14.2 & 0.36 \\
$D_{50}=1.9 \mathrm{~mm}$ & & & & & & & & \\
\hline $\begin{array}{l}\text { Prototype } \\
h=40 \mathrm{~m}, \\
D_{50}=75 \mathrm{~mm}\end{array}$ & 10.6 & 10.7 & 1.39 & 0.90 & 0.64 & 2.38 & 31.7 & 0.79 \\
\hline
\end{tabular}

\section{Analysis and discussion of the flat bed case}

Lomonaco (1994) included tests on the stability of gravel/stones on a flat bed. This case is almost similar to the case with a protection of the seabed on either side of the mound, cf. Figure 1. The analysis of this flat bed stability data are, for "Waves only" cases, carried out in view of the statistical distribution of the wave shear stresses at the bottom, Myrhaug (1995).

The maximum shear stress on the seabed under waves is expressed as:

$$
\tau_{b m}=\frac{1}{2} \rho_{w} f_{w} u_{\delta m}^{2}
$$

Myrhaug (1995) deals with bottom friction beneath random waves. The waves are described as a stationary Gaussian narrow-band random process. According to Myrhaug, the bed orbital displacement is under this assumption given as:

$$
\begin{aligned}
& a_{\delta}(t)=A_{\delta m}(\varepsilon t) \cos [\omega t+\Phi(\varepsilon t)], \text { and the bed orbital velocity as: } \\
& u_{\delta}(t)=\frac{d a(t)}{d t}=u_{\delta m}(\varepsilon t) \sin \left[\omega t+\Phi(\varepsilon t)-\frac{\pi}{2}\right]+O(\varepsilon) ; \text { where } u_{\delta m}(\varepsilon t)=\omega A_{\delta m}(\varepsilon t)
\end{aligned}
$$

and $\omega=2 \pi / T, t$ is time, $\Phi$ is a phase angle and $\varepsilon$ is a small parameter. Myrhaug (1995) used the following relations for the friction factor $f_{w}$ and where herein the different flow regimes are defined according to Madsen and Wood (2002):

$$
\begin{array}{ll}
\text { Laminar flow (i.e. } \left.R_{w}=u_{\delta m} A_{\delta m} / v<2000\right): & f_{w}=2 R_{w}^{-0.5} \\
\text { Smooth turbulent (i.e. } \left.R_{w}>2000 \text { and } R_{s}=k_{s} u * / v<3.3\right): & f_{w}=0.0450 R_{w}^{-0.175} \\
\text { Rough turbulent (i.e. } \left.R_{w}>2000 \text { and } R_{s}=k_{s} u * / v>3.3\right): & f_{w}=1.39\left(\frac{A_{\delta}}{z_{0}}\right)^{-0.52}
\end{array}
$$

Myrhaug found that the statistical distribution of the maximum shear stress, $\tau_{b m}$, under each wave cycle followed a Weibull probability distribution function, with different values of parameters for laminar flow, smooth flow and turbulent flow: 
Laminar flow:

$$
P_{\tau_{b m}}(\xi)=1-\exp \left(-\xi^{2}\right) ; \quad \xi=\frac{\tau_{b m}}{\rho_{w} u_{*_{L}}^{2}} \geq 0
$$

Smooth turbulent flow:

$$
P_{\tau_{b m}}(\xi)=1-\exp \left(-\xi^{1.212}\right) ; \quad \xi=\frac{\tau_{b m}}{\rho_{w} u_{* S}^{2}} \geq 0
$$

Rough turbulent flow:

$$
P_{\tau_{b}}(\xi)=1-\exp \left(-\xi^{1.35}\right) ; \quad \xi=\frac{\tau_{b m}}{\rho_{w} u_{* R}^{2}} \geq 0,
$$

where $u_{*_{L}}^{2}=\frac{1}{2} \cdot 2 R_{r m s}^{-0.175} u_{r m s}^{2} ; u_{*_{S}}^{2}=\frac{1}{2} \cdot 0.0450 R_{r m s}^{-0.175} u_{r m s}^{2} ; u_{*_{R}}^{2}=\frac{1}{2} \cdot 1.39\left(\frac{A_{r m s}}{z_{0}}\right)^{-0.52} u_{r m s}^{2}$

in which $A_{r m s}$ is the root-mean-square value of the water particle excursion at the bottom, $u_{r m s}$ the rootmean-square value of the near bed water particle velocity amplitudes and $R_{r m s}=u_{\mathrm{rms}} \cdot A_{\mathrm{rms}} / v$ is the Reynolds number at the bottom for irregular waves. The rms-values are related to the zeroth moments of the amplitude and velocity spectral densities, respectively. Note that the distribution of the shear stress for the laminar case is a Rayleigh distribution.

In the derivations of the statistical distributions of the shear stress it has been assumed that the flow conditions are laminar, smooth or rough for all the waves in the considered sea state. However, this may not be the case, especially for laboratory conditions. The flow may be laminar for the smallest waves, smooth for intermediate waves and rough for the largest waves.

The critical shear stress $\tau_{c r}$, i.e. the stress beyond which the stones start to move, is given in Soulsby and Whitehouse (1997) and Soulsby (1997) as mean value throughout a large range of $\mathrm{D}_{*-}$ values, including only current, only waves and a combination of waves and currents acting simultaneously with the formula:

$$
\theta_{c r}=\frac{0.24}{D_{*}}+0.055\left[1-\exp \left(-0.020 D_{*}\right)\right]
$$

where $\theta_{c r}=\tau_{c r} /\left(\rho_{w} g \Delta D\right)$ is the critical Shields parameter and $D_{*}=\left[\frac{g \Delta}{v^{2}}\right]^{1 / 3} \cdot D$, where $v$ is the kinematic viscosity of the water.

Lomonaco (1994) used stones with $D_{50}=4.34 \mathrm{~mm}$ for the flat bed case. The critical shear stress, for these stones according to the Eq. (12) is $\tau_{c r}=3.6 \mathrm{~N} / \mathrm{m}^{2} . D_{50}$ has been used as $D$ in Eq. (12) and the value of $D_{*}$ is then $D_{*} \approx 95$. It should be remembered that $\tau_{c r}$ is obtained from test data on the start of movement of the sand/stone grains and that there is scatter in the data. Examining the Shields diagrams shown in Soulsby and Whitehouse (1997) for $D_{*} \approx 95$ for the "only wave case" gives a minimum, mean and maximum critical shear stress of $\tau_{c r \text {, min }}=4.2 \mathrm{~N} / \mathrm{m}^{2}, \tau_{c r \text {, mean }}=6.2 \mathrm{~N} / \mathrm{m}^{2}$ and $\tau_{c r \text {, max }}=9.1 \mathrm{~N} / \mathrm{m}^{2}$.

The statistical distribution of the bed shear stresses in this case is carried out under the assumption that the flow is "rough, turbulent". Closer examinations showed this was the conditions in this case for the largest waves. Figure 6 shows the calculated statistical distribution of the shear stresses for one of the test conditions of Lomonaco (1994), flat base case. The $\tau_{c r \text { min }}, \tau_{c r \text {,mean }}$ and $\tau_{c r \text {,max }}$ is also marked in Figure 6. Similar statistical distributions have also been calculated for other of Lomonacos's test cases.

The statistical distribution of the shear stresses is obtained under the assumption that the Rayleigh distribution applies for the wave heights and that the wave spectrum is narrow. As often done in coastal engineering the calculation has been assumed to be valid also for a JONSWAP spectrum with a $\gamma$-factor $=2.2$.

The maximum shear stress will depend on the maximum wave height. The ratio of the maximum wave height to $H_{s}, H_{\max } / H_{s}$. vs. $H_{s}$ for Lomonaco (1994) tests are shown in Figure 7 . The ratio $H_{\max } / H_{\mathrm{s}}$ is fairly low, which frequently is seen from tests in wave flumes and wave basins. One reason for this is probably limitations in capability of wave generators to generate the larger waves. Assuming that the wave heights are Rayleigh distributed the probability that the maximum wave height is not exceeded during the Lomonacos's tests can be calculated. It is then assumed that the same probability applies for the shear stress also. Based on this assumption the damage parameter $S / \sqrt{N}$ vs. $\tau_{\max }$ has been plotted as shown in Figure $8 . \tau_{90}$, e.g. the $90 \%$ probability of not being exceeded has, somewhat arbitrary, also been plotted for Lomonacos's flat base case. $\tau_{90}$ is close to what might be designated the significant shear stress, $\tau_{s} \approx \tau_{87}$. The minimum, mean and maximum critical shear stresses are also marked in Figure 8.

For the lowest damage value, $S / \sqrt{N}=0.04$, the calculated maximum shear stress does not exceed the critical shear stress. However, as mentioned, there is some uncertainty on the value of the 
critical shear stress. According to the calculations $\tau_{c r}$ is exceeded for quiet many of the waves, some $8 \%$, for the highest damage values, $0.4<S / \sqrt{N}<0.6$, Figure 8 . If a damage $S=50$ or $S / \sqrt{N}=1.10$ for $N=2000$, is accepted, the flat bed structures tested by Lomonaco are considered to be stable.

This approach to stability considerations of flat bed stone structures represents a new approach and should be further explored to obtain a relation between $S / \sqrt{N}$ and $\tau_{\max }$ or $\tau_{90}$ or some other fracture of $\tau$, both for the flat bed and for the mound case. For a mound some "new" critical Shields parameter, $\theta_{c r, m o u n d}$, should be obtained.

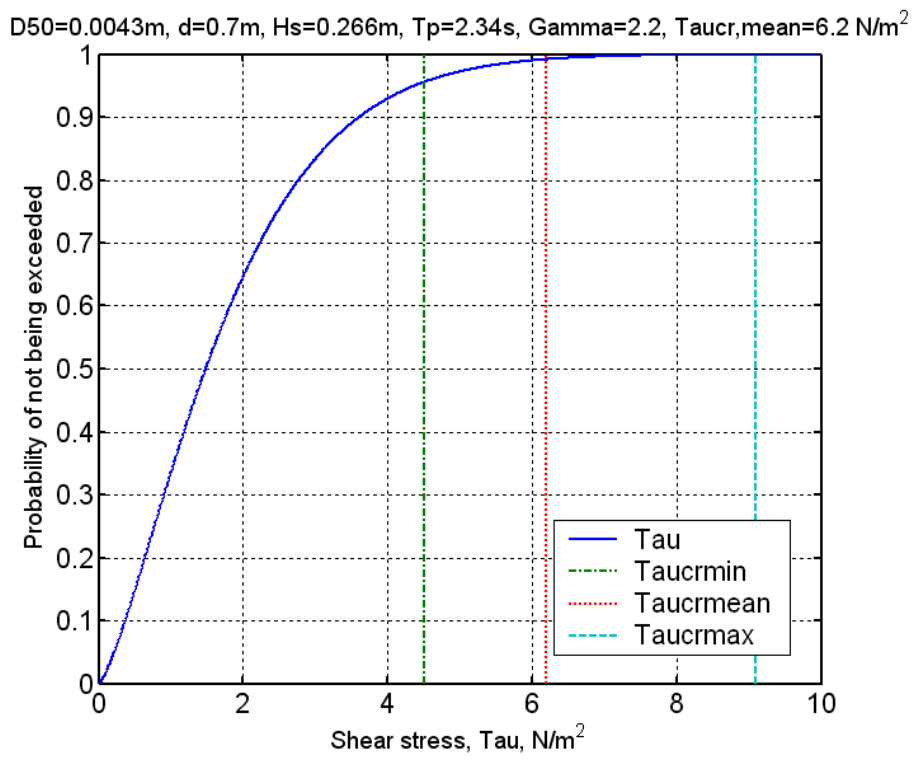

Figure 6. Lomonaco (1995) flat bed case. Probability of not exceeding a certain shear stress. $\boldsymbol{h}=\mathbf{0 . 7 0} \mathrm{m}, \boldsymbol{H}_{\mathrm{s}}=$ $0.266 \mathrm{~m}, T_{p}=2.34 \mathrm{~s}$, JONSWAP wave spectrum with $\mathrm{Y}=2.2 . \tau_{\mathrm{cr}, \min }=4.2 \mathrm{~N} / \mathrm{m}^{2}, \tau_{c r, \text { mean }}=6.2 \mathrm{~N} / \mathrm{m}^{2}$ and $\tau_{c r, \text { max }}=9.1$ $\mathrm{N} / \mathrm{m}^{2}$.

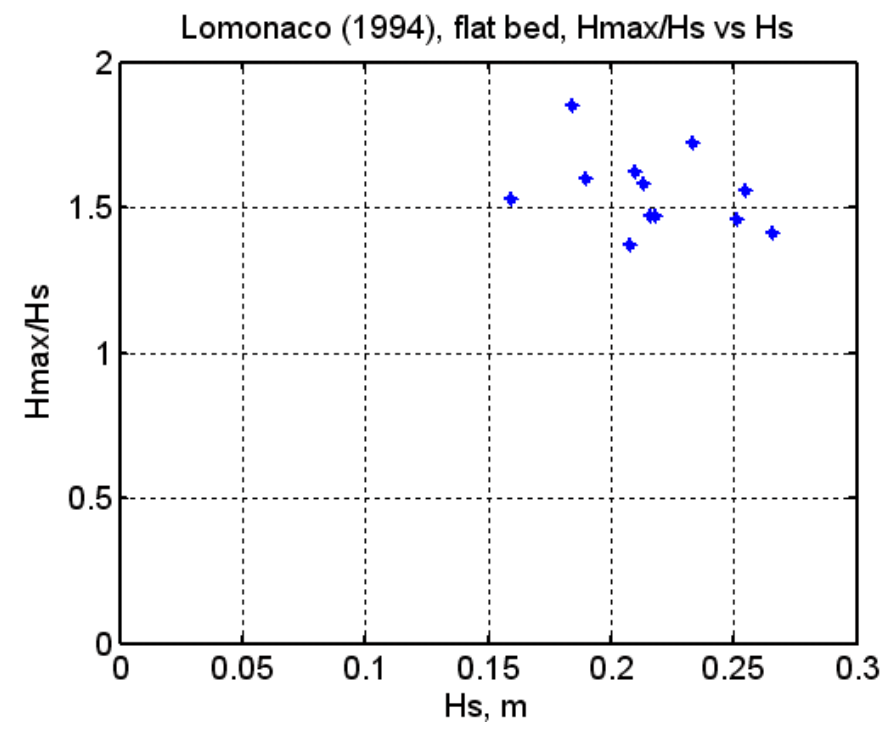

Figure 7. Ratio $H_{\max } / H_{s}$ vs $H_{s}$ during Lomonaco's tests, flat bed case. 


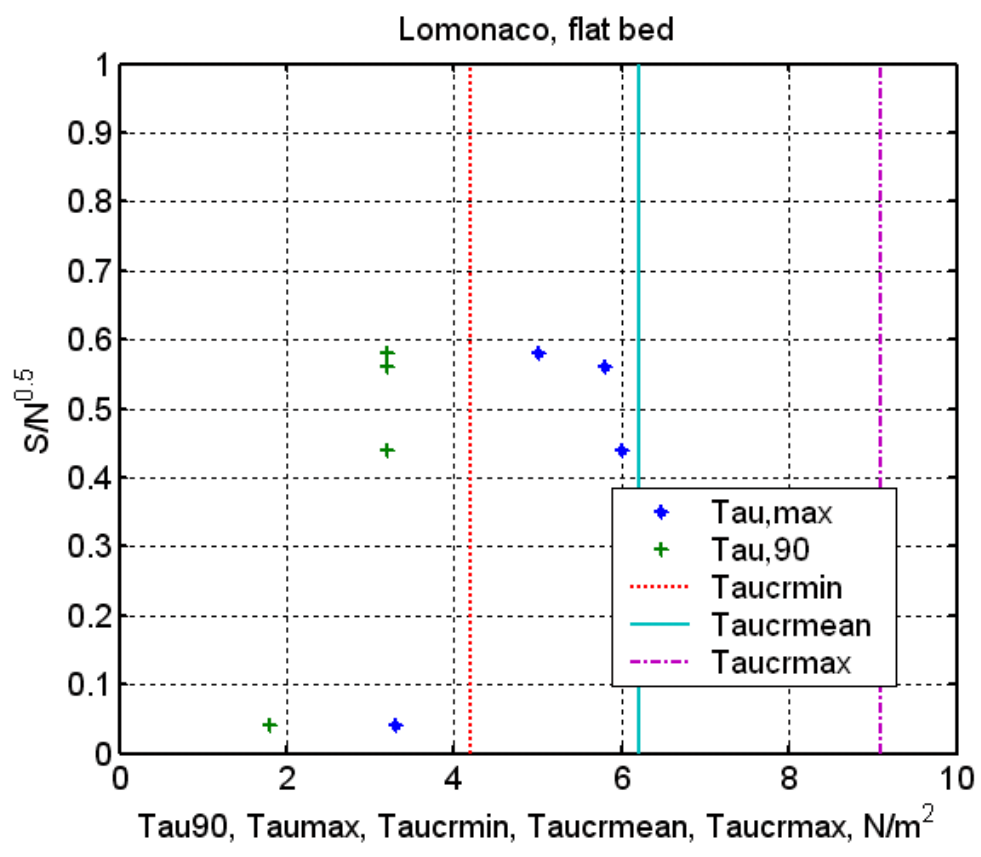

Figure 8. Lomonaco (1994), flat bed case. The damage parameter $S / \sqrt{N}$ vs $\boldsymbol{T}_{90}$ and $\boldsymbol{\tau}_{\max } . \boldsymbol{T}_{\mathrm{cr}, \min }=4.2 \mathrm{~N} / \mathrm{m}^{2}$, $T_{\mathrm{cr}, \text { mean }}=6.2 \mathrm{~N} / \mathrm{m}^{2}$ and $T_{\mathrm{cr}, \max }=9.1 \mathrm{~N} / \mathrm{m}^{2}$.

\section{CONCLUSIONS}

Tests on the stability against waves of granular material (breakwaters, near bed structures, sand beds, sand bed protections et.) show inherent test results scatter. The scatter is due to several factors e.g. variation of the stone size, stone orientation, wave and current turbulence, observation procedures. Stability calculation methods are mainly based on some average value of the test results. Normally no safety factor is used on this average value approach. This may be because traditionally this approach has been taken for breakwaters and there has been tradition for accepting some repair damage on rubble mound breakwaters. However, newer approaches have been to carry out probabilistic analysis of performance of structures, including mound structures, to actions from waves and currents, ISO 21650 (2007).

\section{Mounds}

It is recommended that the damage of homogenous mounds with slopes in the range $\operatorname{tg} \beta<1: 2-$ 1:3 over pipelines is calculated for small damage values as follows:

$$
S=3.0 M_{p} \sqrt{N} \text { for } M_{p}<2.0
$$

It remains to decide what the acceptable damage is. Vidal et al. (1998) recommended that a mound over a sewage outfall should be designed for $M_{p}<0.06$ giving $S=3.0$. The sewage outfall pipeline had fairly large stones, $W_{50}=123,386$ and $700 \mathrm{~kg}$, placed in two layers. A rock mound over a pipeline with a crest width of $B=2 \mathrm{~m}$ and $D_{n 50}=0.10 \mathrm{~m}$ means that there are on the average approximately $B / D_{n 50}=2.00 / 0.10=20$ stones across the crest width. With $S=50$ and $S=100$ it means that approximately 2.5 and 5 layers of the stones will be removed respectively or $0.25 \mathrm{~m}$ and $0.50 \mathrm{~m}$. The mound will probably cover the pipeline with at least $0.50 \mathrm{~m}$. A damage of $S=50$ should probably be acceptable. It is recommended that "Acceptable damage" is therefore set to $S=50$.

In general it is noted that in calculations of the stability of granular materials (mound breakwaters, mounds over pipelines etc.) exposed to waves the calculation formulas are based on some mean values of test results. Further probability of damage analysis should include the inherent scatter of test results and the uncertainty of wave climates at the location under consideration.

The scatter in the test results especially for low mobility parameters, the important range for gravel mounds over pipelines in "deep" water, induces uncertainties in the design basis. Improved kinematics of the waves when passing over a mound should be used in future work on the stability of pipeline mounds, and may be a better understanding of the interaction of the water and the stones on the mound, may be by a "new" shear stress concept. 
Analysis of results of surveys (profiles) of existing mounds over pipelines with documentation of wave conditions between survey periods may also be useful.

\section{Flat bed}

A new approach to investigate the stability of flat bed stone protection layers has been outlined. This approach is based on work by Myrhaug (1995) on the statistical distribution of wave-induced shear stresses. Further experimental work should be carried out to obtain improved stability criteria. The same approach should probably be taken for mounds also. But then a "mound Shields number" should be established.

\section{NOMENCLATURE}

$a_{\delta}(t) \quad$ bed orbital displacement of water particles

$A \quad$ damage area

$A_{\delta m} \quad$ orbital amplitude of wave motion at the bed

$B \quad$ width of mound berm

$D \quad$ sieve grain size diameter

d pipe diameter

$D_{n 50}=\left(\frac{W_{50}}{\rho_{s}}\right)^{\frac{1}{3}}$, grain diameter for which $50 \%$ of the grains by mass are finer

$D_{p} \quad$ sieve grain diameter for which $p \%$ of the gravel/stones are smaller

$f_{g} \quad$ grain gradation factor

$f_{w} \quad$ wave friction factor in $\tau_{b}=\frac{1}{2} \rho_{w} f_{w} u_{\delta}^{2}$

$g \quad$ acceleration of gravity $\left(=9.8 \mathrm{~m} / \mathrm{s}^{2}\right)$

$H$ wave height

$h \quad$ water depth around the mound

$h_{c} \quad$ water depth above the mound

$H_{s} \quad$ significant wave height

$k_{c} \quad$ wave number calculated using $h_{c}$ as depth

$k_{s}=2.5 D_{50}$, sand roughness

$M_{p}=\frac{u_{\delta m}^{2}}{g \Delta D_{n 50}}$, mobility parameter

$N \quad$ number of waves

$N_{s}=\frac{H}{\Delta D_{n 50}}$, stability number

$P \quad$ probability of non-exceedance

$R_{s}=\frac{k_{s} u_{*}}{v}$, bed roughness Reynolds number

$R_{w}=\frac{u_{\delta m} A_{\delta m}}{v}$, near bed wave Reynolds number

$S=\frac{A}{D_{n 50}}$, non-dimensional damage on a gravel or rock structure

$t \quad$ time

$T_{m} \quad$ mean wave period

$U \quad$ background current speed

$u_{*}=\sqrt{\frac{\tau_{b}}{\rho_{w}}}$, friction velocity

$u_{\delta} \quad$ orbital amplitude of horizontal particle velocity at sea bed

$u_{\delta m} \quad$ maximum orbital amplitude of horizontal particle velocity at sea bed

$W_{50} \quad 50 \%$ of the stones are heavier than $W_{50}$

$z_{0} \quad=k_{s} / 30$ for rough turbulent flow;

$=v /\left(9 u_{*}\right)$ for smooth turbulent flow.

$\rho_{s} \quad$ mass density of the gravel/stones

$\rho_{w} \quad$ mass density of the water

$\Delta=\frac{\rho_{s}}{\rho_{w}}-1$ 


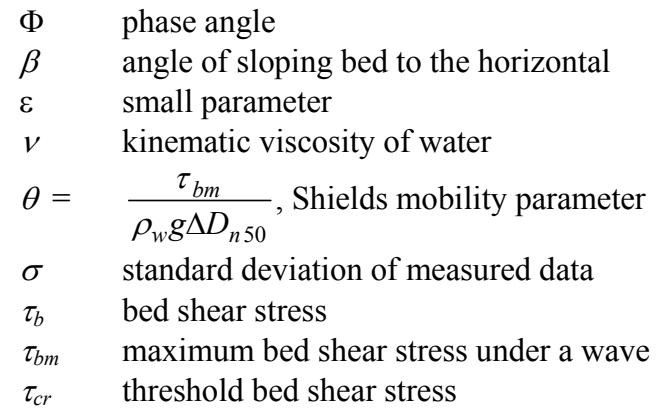

\section{ACKNOWLEDGEMENTS}

The Authors thank ConocoPhillips for the financial support to build the water current system in the wave flume. The Valle Scandinavian Scholarship and Exchange Program at the University of Washington, Seattle, USA, are acknowledged for providing a scholarship for Colin Kuester to study at NTNU. The Authors also acknowledge fruitful discussions with Professor Dag Myrhaug, NTNU.

\section{REFERENCES}

CIRIA, CUR and CETMEF. 2007: The Rock Manual. The use of rock in hydraulic engineering. $\left(2^{\text {nd }}\right.$ edition). C83, CIRIA, London.

ISO 21650. 2007: Actions from waves and currents on coastal structures. International Standard, First edition, 2007-10-15.

Kuester, C. 2007: Waves and currents on near-bed structures. Data summary report. Norwegian University of Science and Technology, Department of Civil and Transport Engioneering/Valle Scandinavian Scholarship and Exchange Program. June 2007.

Lomonaco, P. 1994: Design of rock cover for underwater pipelines. MSc-thesis International Institute for Infrastructural, Hydraulic and Environmental Engineering, Delft Technological University, Delft, The Netherlands.

Lomonaco, P., Vidal, C., Losada, I.j. and Mendez, F.J. 2003: Wave height, pressure and velocity CDF's (cumulative distribution function) around rubble protections for submarine outfalls. Proceedings of the conference Coastal Strucures 2003, 26 - 30 August 2003, Portland, Oregon, USA. American Society of Civil Engineers (ASCE).

Madsen, Ole S. and Wood, William. 2002. Sediment Transport Outside the Surf Zone In: Coastal Engineering Manual, Part III, Coastal Sediment Processes, Chapter III-6, Engineer Manual 11102-1100, U.S. Army Corps of Engineers, Washington, DC.

Myrhaug, D. 1995: Bottom friction beneath random waves. Coastal Engineering, 24 pp 259-273, 1995.

Myrhaug, D., Holmedal, L.E., Simons, R.R. and MacIver, R.D. 2001: Bottom friction in random waves plus current flow. Coastal Engineering, 43 pp 75 - 92, (2001).

Soulsby, R.L. and Whitehouse, R.J.S. 1997: Threshold of sediment motion in Coastal Environments. Proc. Combined Australasian Coastal Engineering and Ports Conference, Christchurch, 1997.

Soulsby, R.L. 1997: Dynamics of marine sands. Publisher Thomas Telford, London, UK.

Tørum, A., Kuester, C. and Arntsen, Ø.A. 2008: Stability against waves and currents of rubble mounds over pipelines. Norwegian University of Science and Technology, Department of Civil and Transport Engineering, Report no. BAT/MB-R1/2008.

Van Gent, M.R.A. and Wallast, I 2001: Stability of near-bed structures and bed protections. Analysis of physical model tests with waves and currents. Delft Cluster report DC030204H3804, Delft Hydraulics, December 2001, Delft, The Netherlands.

Van Gent, M.R.A. and Wallast, I. 2002: Stability of near-bed structures under waves and currents. Proceedings of the $28^{\text {th }}$ International Coastal Engineering Conference, 7 - 12 July 2002, Cardiff, Wales, Great Britain. World Scientific Publishing Co. Pte Ltd.

Vidal, C., Losada, I., Martin, F.L. 1998: Stability of near-bed rubble mound structures. Proceedings of $26^{\text {th }}$ International Conference on Coastal Engineering, $22-26$ June 1998, Copenhagen, Denmark. ASCE.

Vidal, C., Lomonaco, P. and Martin, F.L. 2002: Prototype analysis of stability of rubble mound protections for submariune outfalls. Proceedings of the $28^{\text {th }}$ International Coastal Engineering Conference, 7 - 12 July 2002, Cardiff, Wales, Great Britain. World Scientific Publishing Co. Pte Ltd. 
Vidal Pascual, C., Lopez Mera, F. and Losada, I. 2007: Stability analysis of low-crested and submerged rouble mound breakwaters: Relation between flow characteristics and measured damage and stabilty formulae for low-crested and submerged breakwaters. Proceedings of the international conference on Coastal Structures 2007, 1 - 5 July 2007, Venice, Italy. 